\title{
Who stole the sugar? Recurrent hypoglycemia in three women
}

\author{
Katarzyna Gontarz, Anna Barczykowska, Paulina Głowacka, \\ Aleksandra Mędza, Małgorzata Młynarkiewicz, Jakub Obrębski, \\ Małgorzata Szczurek, Aleksandra Wielewicka, Kukasz Obołończyk $\odot$, \\ Piotr Wiśniewski
}

Student Scientific Club at the Department of Endocrinology and Internal Diseases Medical University of Gdańsk, Poland

\begin{abstract}
This article presents 3 cases that highlight one of the factitious disorders named Munchausen Syndrome (MS). It is defined as intentional simulation or self-induction of disease symptoms to gain attention of others and to be perceived as an ill person. Early recognition of factitious disorders is a challenge for non-psychiatrists, as its clinical symptoms vary significantly among patients. In this paper we present three women with recurrent episodes of hypoglycemia, who were eventually diagnosed with MS. Our aims were to share the diagnostic clues that can suggest the presence of a factitious disorder, to highlight the analysis of patient's medical history and to suggest the potential the ethical dilemmas involved in caring for such patients.

Keywords: factitious disorder - Munchausen Syndrome - hyperinsulinemia • C-peptide
\end{abstract}

\section{Citation}

Gontarz K, Barczykowska A, Głowacka P, Mędza A, Młynarkiewicz M, Obrębski J, et al. Who stole the sugar? Recurrent hypoglycemia in three women. Eur J TransI Clin Med 2018;1(1):70-75.

DOI: $10.31373 /$ ejtcm/92068

\section{Introduction}

Munchausen Syndrome (MS) is a rare factitious psychiatric problem rooted in the patient's need of gaining attention and being perceived as an ill/needing help [1]. It is defined by a classic triad of: deliberate stimulation of disease, traveling from one healthcare institution to another (peregrination) and pathological lying (pseudologia fantastica) [3-4]. MS is associated with severe emotional distress and/or personality disorders. Most frequently it affects people with history of depression (or other psychiatric conditions), women and health care workers [5]. Typically, the patient's history reveals frequent hospital admissions, aggressive treatments, therapies and invasive investigation procedures. The patient's textbook knowledge of the illness also should draw the clinician's attention. The clinical presentation may involve physical symptoms (e.g. burns, lesions, Cushing's syndrome symptoms, hyperthyroidism, hypoglycemia, pheochromocytoma, diarrhea, anemia and coagulopathy) and/or psychological symptoms [6]. MS was first described in 1951 by Richard Asher [2].

The diagnostic process demands exclusion of any organic disorders which requires systematic assessment

\section{Corresponding author:}

Katarzyna Gontarz, Medical University of Gdańsk, Poland, e-mail.: katarzyna.gontarz.92@gmail.com

Available online: ejtcm.gumed.edu.pl

Copyright ${ }^{\circledR} \quad$ Medical University of Gdańsk

This is Open Access article distributed under the terms of the Creative Commons Attribution-ShareAlike 4.0 International (CC BY-SA 4.0); license available at: https:// creativecommons.org/licenses/by-sa/4.0/. 
of the physical symptoms and also psychological assessment and psychiatric examination. Such diagnostic process is time- and resource-consuming, thus MS can be underdiagnosed.

In this paper authors present a short discussion about three women with MS: a 43-year-old diabetic with a history of depression and alcohol dependence syndrome, a 21-year-old with recurrent episodes of hypoglycemia and a 31-year-old with episode of loss of consciousness with accompanying hypoglycemia.

\section{Patient 1}

A 43-year-old woman was admitted to Department of Endocrinology and Internal Medicine, because of recurrent episodes of hypoglycemia. She was previously hospitalized and diagnosed at another hospital due to symptoms of hypoglycemia. Her medical history included alcohol dependence syndrome, depression, hepatic cirrhosis and peptic ulcer disease. In 2007 she was diagnosed with diabetes mellitus (after an episode of acute pancreatitis) and since then has been treated with insulin (20 units per day).

Starting 1,5 months prior to the present admission, the patient had multiple episodes of hypoglycemia accompanied by loss of consciousness. Those episodes did not correlate with meals, never occurred at night nor when the patient was alone (family members always witnessed them). Although the insulin treatment was stopped, her symptoms continued. One episode of hypoglycemia was observed during her first hospital stay (blood glucose level of $25 \mathrm{mg} \%$ and insulin level of 394,5 $\mu \mathrm{U} / \mathrm{ml})$. For technical reasons the C-peptide was not assessed at that time. Abdominal CT scan did not show any focal lesion in pancreas. After her second hospitalization due to hypoglycemia, the patient was referred to our department with a suspicion of insulinoma. In physical examination she was in good general condition, her mental state was also normal, and she was afraid of the possibility of having a pancreatic tumor.

On the first day at our clinic the patient's condition worsened and her blood tests once again revealed low glucose and again inadequately high plasma insulin and c-peptide levels (see Table 1). Such results are typical for exogenous hyperinsulinemia and MS.

Table 1. Lab results during overt hypoglycemia

\begin{tabular}{|l|c|c|}
\hline & $\begin{array}{c}\text { referent } \\
\text { ranges* }\end{array}$ & result \\
\hline Glucose $(\mathrm{mg} \%)$ & $60-99$ & 32 \\
\hline Plasma insulin $(\mu \mathrm{U} / \mathrm{ml})$ & $2-25$ & 118,1 \\
\hline Plasma c-peptide $(\mathrm{ng} / \mathrm{ml})$ & $0,9-7,1$ & $<0,1$ \\
\hline
\end{tabular}

*laboratory ref. ranges are related to healthy individuals

However, the patient denied possession of an insulin pen or injecting herself with insulin without doctors' instructions. On the following day, while she was being psychiatrically consulted, her personal belongings were checked and two insulin pens were found in her bag. When confronted about this, the patient once again denied possession of insulin. Upon the request of the staff, the patient returned the pens insisting she did not know about them. Careful examination of the skin revealed injection marks on her abdomen which most likely resulted from insulin administration. The patient claimed that the bruises were caused by a leather belt. No further episodes of hypoglycemia were reported and the patient's insulin levels gradually decreased (see Table 2).

To rule out insulinoma we performed a 72 hours fasting glucose test. The patient's lowest recorded glucose level was $97 \mathrm{mg} \%$, thus excluding insulinoma. Unfortunately the patient indeed suffered from "real" diabetes mellitus, so it was difficult to plan her further treatment.

Table 2. Short version of glucose profile before (over double line) and after (below double line) insulin pens confiscation

\begin{tabular}{|c|c|c|c|}
\hline date & glucose $(\mathrm{mg} \%)$ & insulin ( $\mu \mathrm{U} / \mathrm{ml})$ & c-peptide (ng/ml) \\
\hline 3/09/2009 8:36 p.m. & 32 & 118.1 & $<0.1$ \\
\hline 4/09/2009 3:00 a.m. & 103 & - & - \\
\hline 4/09/2009 7:00 a.m. & 342 & 一 & - \\
\hline 4/09/2009 11:00 a.m. & 175 & - & - \\
\hline 4/09/2009 1:00 p.m & $37(32)$ & 64.9 & 0.503 \\
\hline 4/09/2009 8:00 p.m. & $48(33)$ & 28 & $<0.1$ \\
\hline 4/09/2009 11:00 p.m. & 48 & 一 & 一 \\
\hline 5/09/2009 3:00 a.m. & 82 & 一 & 一 \\
\hline 5/09/2009 11:00 a.m. & 109 & 12.2 & 0.387 \\
\hline 5/09/2009 3:00 p.m. & 109 & 10.0 & 0.471 \\
\hline 5/09/2009 7:00 p.m. & 157 & 10.2 & 1.36 \\
\hline 6/09/2009 7:00 a.m. & 94 & 4.5 & 0.516 \\
\hline 6/09/2009 5:00 p.m. & 183 & 21.4 & 5.43 \\
\hline 6/09/2009 9:00 p.m. & 216 & - & - \\
\hline
\end{tabular}


As a "lesser evil" we decided to prescribe metformin (patient with stable liver cirrhosis) and inform her family physician about difficulties with treating her hypoglycemia.

\section{Patient 2}

A 21-year-old woman was admitted our department because of recurrent hypoglycemia. Previously she was hospitalized several times due to bronchial asthma attacks. During her last hospitalization due to an episode of hypoglycemia (8 months ago) she was instructed to self-measure glycemia at home. She claimed that her blood sugar maintained between $50-160 \mathrm{mg} \%$ fasting and $150-240 \mathrm{mg} \%$ after meal. Therefore, she was diagnosed with steroid-induced diabetes with a suggestion of insulin therapy. The patient claimed that she refused this treatment and had never taken any insulin injections. 5 months ago, during hospitalization at an allergology department in a different province, the patient complained of dyspnea with anxiety and feeling of weakness, hyperhidrosis and tachycardia. Laboratory tests showed decreased blood glucose level (17 mg\%), increased plasma insulin level $(>600 \mu \mathrm{U} / \mathrm{ml})$ and the C-peptide was not measured. Due to that fact, insulinoma was suspected, but the abdominal CT revealed a normal pancreas without any focal lesions. Patient was referred to our Clinic.

At the day of admission she was in a good general condition with normal vital signs. The results of physical examination were unremarkable, besides injection-like marks on skin of right thigh. The patient did presented absolutely no signs and symptoms of bronchial asthma. Interestingly, she brought with her a very large set of medical records and spoke using professional medical terminology. We considered this patient as high risk of MS.

We started typical 72 hours fasting test. However, during the first day of fasting the test had to be stopped because of seizures, sweating and tachycardia. It was impossible to take venous blood samples, glucometer-measured glycemia was $25 \mathrm{mg} \%$. After administration of concentrated glucose, signs of hypoglycemia disappeared and blood sugar level normalized. 72 hours fasting plasma glucose test was performed again the next day and it was terminated around seven hours later with glucose level $36 \mathrm{mg} \%$. The results were typical for exogenous hyperinsulinemia (see Table 3).

The patient questioned by our staff confirmed having taken insulin injections. She voluntarily gave away her insulin pen (Novorapid) and assured she would undergo psychiatric and psychologic therapy. The consulting psychiatrist diagnosed personality disorders and recommended their further ambulatory tratment and a consultation of neurologist with an EEG examination.

\section{Patient 3}

A 31-year-old woman was urgently admitted to our department due to an episode of loss of consciousness with accompanying hypoglycemia. On the day before the episode, the patient complained of fatigue and weakness. According to the witness (her husband), the loss of consciousness appeared when the patient was lying down on the sofa. The ambulance team diagnosed hypoglycemia with a blood glucose level of 40 mg\% (at 22:00). After admission to the local Emergency Department she was further diagnosed with mild hypokalemia, bradycardia ( $38 / \mathrm{min}$ ) and hypoglycemia (60 mg\%), with no obvious pathologies in the abdominal ultrasound. The patient was transferred to our Clinic for further diagnosis. Upon admission she had normal vital signs and no other obvious abnormalities. Insulin and c-peptide levels were ordered at the Emergency Department, but the results were not going to be available until the following day.

Her medical history included two past episodes of hypoglycemia. In July 2014, the patient was admitted to a hospital in a different province, where she was diagnosed with dehydration, hypokalemia, hypoglycemia,

Table 3. Results of fasting plasma glucose test performed on the second day of hospitalization

\begin{tabular}{|c|c|c|c|}
$\begin{array}{c}\text { time } \\
\text { (minutes) }\end{array}$ & $\begin{array}{c}\text { blood glucose level } \\
(\mathbf{m g} / \%)\end{array}$ & $\begin{array}{c}\text { plasma insulin level } \\
(\boldsymbol{\mu U} / \mathbf{m l})\end{array}$ & $\begin{array}{c}\text { plasma c-peptide level } \\
(\mathbf{n g} / \mathbf{m l})\end{array}$ \\
\hline $0^{\prime}$ & 80 & 7,4 & - \\
\hline $145^{\prime}$ & 152 & - & - \\
\hline $205^{\prime}$ & 80 & - & - \\
\hline $265^{\prime}$ & 50 & 26,9 & 0,29 \\
\hline $325^{\prime}$ & 36 & 32,3 & 0,21 \\
\hline $340^{\prime}$ & 38 & - & - \\
\hline $390^{\prime}$ & 50 & 56,8 & 0,13 \\
\hline $420^{\prime}$ & 25 & & - \\
\hline
\end{tabular}


duodenal ulcer, gastritis, hiatal hernia, bronchitis and urogenital infection. In January 2015, she was admitted to her local Emergency Department due to symptomatic hypoglycemia (34 $\mathrm{mg} \%$ ). At that time she refused the transfer to our Clinic for family reasons. In addition, her medical history included a right-sided ovariectomy and appendectomy and no diagnosed chronic illnesses.

The patient stated that she regularly ate sufficient amounts of food throughout the day. However, she confirmed a declined appetite, most probably due to stress, and weight loss of about $3 \mathrm{~kg}$ in 2 weeks. She reports also everyday pains of epigastrum, not related to food intake. She negated any drug intake on permanent basis (insulin included).

The diagnosis of the causes of hypoglycemia was initiated (daily glycemic profile with glucose levels from 84 to $91 \mathrm{mg} \%$, daily insulin serum levels from 4,7 to 6,8 $\mathrm{uU} / \mathrm{ml}$ ), but not completed. On her own request, the patient was discharged from the hospital due to family reasons. She was informed about the possible risks of hypoglycemia and the lack of appropriate diagnosis as well as how to recognize the symptoms of low glucose level. A few hours later we received results from the ED: insulin $86,2 \mathrm{uU} / \mathrm{ml}$ and c-peptide $0,17 \mathrm{ng} / \mathrm{ml}$. Post factum we diagnosed MS.

\section{Discussion}

Diagnosis of MS may be challenging to confirm since the patient requires numerous diagnostic tests and thorough observation of his/her behavior and clinical history. Things that should arouse suspicion of the disorder are unexplained course of disease, signs of prior treatment, enthusiasm to undergo surgery, multiple hospitalizations and visits to various outpatient healthcare institutions [12]. Although patients 1 and 3 were admitted to different hospitals many times, neither the diagnosis nor treatment were effective or the patient refused further hospitalization. On the other hand, patient 2 had no history of frequent hospitalizations.

It is believed that both the access to the medical information from the internet and working in health professions can facilitate the simulation of symptoms [14]. It is also common for patients with MS to use professional medical terminology when describing their symptoms and other health issues. However, none of our 3 patients had any medical education or work experience.

Another essential features of patients with MS include: the desire to play the role of the patient, no financial benefits from such behavior and having an antisocial or borderline personality disorder [15]. Patient 1's combination of alcohol abuse and family problems may put forward the diagnosis of MS. Furthermore, she suffers from diabetes mellitus, alcohol dependence syndrome, chronic pancreatitis and cirrhosis. In order to confirm an underlying psychiatric cause of the hypoglycemias, we had to take into account organic and exogenous causes.

MS may manifest with a wide range symptoms, limited only by the patient's imagination and will. We would like to focus on common symptoms that are relatively easy to induce because all the necessary "tools" are commonly prescribed and easily available. In addition, information about drug doses and routes are found in the widely available medical literature online or in print. Therefore, we suggest that the following types of endocrine manifestations of MS might be encountered in routine medical practice.

\section{Hyperthyroidism}

An exogenous cause of hyperthyroidism may be the result of taking medicines or drugs containing thyroid hormones. The most commonly it is levothyroxine (T4), however triiodothyronine (T3), thyroid extract, and mixtures of synthetic T4 and T3 can also lead to hyperthyroidism. High amounts of thyroid hormones can cause an excessively high metabolic rate which presents with sudden weight loss, tachycardia, nervousness, anxiety and irritability, tremor, changes in menstruation, sweating and absence of goiter. Interestingly, ophthalmopathy occurs only in patients with Graves' hyperthyroidism, but on the other hand the intentional intake of T4 may induce "real" Graves' disease. The diagnosis is based on thyroid tests. Test results indicate a low TSH, increased or normal free thyroxine (fT4) and/or free triiodothyronine (fT3) level. In that condition radioiodine uptake measurement is often recommended as the first-line investigation, followed by the serum level of thyroglobulin ( $\mathrm{Tg}$ ) to differentiate exogenous hyperthyroidism (with low Tg serum concentration) from all other causes of hyperthyroidism (with high Tg serum concentration). For most patients thyroid hormone intake discontinuation is the only treatment needed [7].

\section{Pheochromocytoma}

Alternately, the symptoms may imitate pheochromocytoma either as a result of epinephrine injections or as conscious altering the autonomic function with Valsalva maneuver [8]. Pheochromocytoma is a catecholamine-secreting tumor that arises from chromaffin cells of the adrenal medulla or the sympathetic ganglia. The most common symptoms of pheochromocytoma are high blood pressure, rapid or forceful heartbeat, profound sweating, severe headache, tremors, paleness in the face, shortness of breath. Anaphylactic reaction kits contain epinephrine only, so disproportion between epinephrine (or its metabolites) and norepinephrine (or its metabolites) is very helpful in diagnosis. The plasma epinephrine: free metanephrine ratio can help to differ- 
entiate between factitious disorder and pheochromocytoma [9].

\section{Hypercortisolism}

Induced hypercortisolism can sometimes be challenging to confirm due to the multiple routes of administering steroids. Patients can use pills, injectable solutions, intravenous drugs and even creams and ointments to induce symptoms. The clinical presentation of hypercortisolism (both endo- and exogenous) may include: hypertension, weight gain (often central obesity, supraclavicular and dorsocervical fat accumulation), hirsutism, plethora, irregular menstruation, decreased libido, irritability, proximal muscle weakness, osteoporosis and fractures, diabetes [10]. Test results depend on type of glucocorticoid. Drugs with structure similar to cortisol (e.g. hydrocortisone) will give high levels of plasma cortisol, with low ACTH levels. This group of patients is much more difficult to diagnose because they have hormonal constellation identical to ACTH-independent (adrenal) Cushing syndrome. Whereas steroids not resembling cortisol (e.g. dexamethasone) will not be detected in laboratory assessments. Such patients will have low cortisol and ACTH levels in hormonal tests. If necessary, imaging examinations such as MRI and CT may be performed to exclude abnormalities of the pituitary or adrenal glands. Dynamic tests as dexamethasone-CRH test and DDAVP stimulation test may be also helpful, but their value is limited [11].

In those cases recurrent hypoglycemic episodes prompted the admission of those 3 patients to the hospital. Most reported cases of factitious hypoglycemia involve young women. Researchers agree that the typical age of onset of this disease is under 30 [13]. Patient 2 and 3 were under 30 when the first episode occurred. However, patient 1 was 43 years old.

The most common initial diagnosis in patients with recurrent hypoglycemia is insulinoma. This disease leads to episodes of hypoglycemia during fasting and after physical activity. It is most commonly diagnosed in adults [16]. Historically the oldest criteria of insulinoma were described as Whipple's triad: symptoms consistent with hypoglycemia, a low plasma glucose concentration and relief of those symptoms after the plasma glucose level is raised [17]. Current biochemical criteria of endogenous hyperinsulinemia include: level of plasma glucose concentration less than $54 \mathrm{mg} / \mathrm{dl}$, insulin concentration greater than $3 \mu \mathrm{U} / \mathrm{ml}$, C-peptide concentration greater than $0,6 \mathrm{ng} / \mathrm{ml}$ [18]. Only the C-peptide level can help distinguish exogenous from endogenous hyperinsulinemia. In our cases, the initial diagnosis of insulinoma was easily excluded by inadequately high levels of insulin and low levels of C-peptide during hypoglycemia episodes. Moreover, in case 1 and 2 CT scans revealed no abnormal pancreatic masses.
Second, another reason of hypoglycemia that had to be considered is nesidioblastosis, also called as hyperinsulinemic hypoglycemia. It is attributed to excessive function and dysplasia of pancreatic b cells [18-19]. That condition we had to consider due to patient's 1 gastric surgery in the past and the absence of night episodes of hypoglycemia. Moreover CT revealed no tumor, which even increase possibility of diagnosis of nesidioblastosis. Nevertheless, C-peptide level was low, thus this hypothesis could be rejected.

Third, hypoglycemia can occur in patient who has undergone gastric surgery. This kind of hypoglycemia is called reactive (postprandial) hypoglycemia. Usually symptoms are directly related to prior meal. Indeed, Patient 1 underwent gastric surgery, however each episode of her hypoglycemia was not associated with meal ingestion and C-peptide level was low.

Another condition to exclude is a rare cause of hypoglycemia named autoimmune hyperinsulinemic hypoglycemia (Hirata syndrome). It is most common in Japan. It results from the presence of endogenous insulin antibodies and antibodies against insulin receptor. Symptoms can be noticed during physical exercises, fasting and postprandial hypoglycemia. The comorbidity of Insulin Autoimmune Syndrome (IAS) and other autoimmune disease is common. In case report described by Wong et al. in 2013 patient with IAS had elevated levels of insulin and C-peptide and also insulin and its receptor antibodies. Whereas all of our patients had low levels of C-peptide during hypoglycemia attacks and no history of other autoimmune diseases [20].

We also ruled out a non-beta cell tumor which can lead to hypoglycemia in two different ways. First, relatively high rates of glucose utilization due to significant size of tumor. Second, overproduction of Insulin-like Growth Factor-2 (IGF-2) by tumor a causes the decrease of glucagon secretion [18, 21]. Here hypoglycemia is related with adequately low blood levels of insulin and C-peptide. In our cases insulin was always high. Moreover, patients 1 and 2 had no pathological masses in the CT scan, so diagnosis of non-beta cell tumor was unlikely.

Finally, the most common cause of hypoglycemia is unintentional and improper use of insulin or antidiabetic drugs (especially sulphonylurea) by patients with diabetes mellitus [22]. In all of the presented cases markedly increased insulin level and the non-corresponding C-peptide levels were compatible with exogenous insulin administration as the cause of hypoglycemia. However, administration of insulin secretagogues leads to elevated insulin and C-peptide level which makes it difficult to differentiate between insulinoma, non-beta cell tumor and autoimmune hyperinsulinemic hypoglycemia. In such situation toxicological tests are necessary. 


\section{Conclusion}

The diagnostic path could have been simpler if the C-peptide level had been measured earlier (e.g. at the time of the first hypoglymic episode) and if physicians were more aware of MS. However physicians rarely suspect the patients' desire to injure themselves, therefore most often this is a diagnosis by exclusion, not inclusion. Including MS in the differential diagnosis might reduce unnecessary medical procedures. However, we must remember that a patient with MS can prevent the physician and staff from making the MS diagnosis by chang- ing the symptoms (way/s of inducing them) or by simply seeking help at a different healthcare facility. Obtaining a psychiatric consultation early can prevent the patient from inflicting serious harm to his/her health as well as can help him/her to address the mental health issues underlying the MS behaviors.

C-peptide levels should be evaluated early in cases of hypoglycemia with atypical course. For a quick and accurate diagnosis, the medical team must focus on the patient's mental status and careful observation of the patient's behavior at the hospital ward.

\section{References}

1. Criddle L. Monsters in the closet: Munchausen syndrome by proxy. Crit Care Nurse. 2010;30(6):46-55.

2. Yates GP, Feldman MD. Factitious disorder: a systematic review of 455 cases in the professional literature. Gen Hosp Psychiatry. 2016;41: 20-8.

3. Turner J, Reid S. Munchausen's syndrome. Lancet. 2002;359(9303):346-9.

4. Sutherland AJ, Rodin GM. Factitious disorders in a general hospital setting: clinical features and a review of the literature. Psychosomatics. 1990;31(4):392-9.

5. Ruiz P, Sadock V, Sadock B. Kaplan and Sadock's Synopsis of Psychiatry: Behavioral Sciences/Clinical Psychiatry. 2014;

6. Asher R. Münchhausen syndrome. Lancet. 1951;1(6650):339-41.

7. Little A, Curtis H, Kellogg B, Harrington M. Munchausen Syndrome Disguised As Gossypiboma: An Interesting Case. Eplasty. 2016;16:ic39.

8. Repper J. Munchausen syndrome by proxy in health care workers. J Adv Nurs. 1995;21(2):299-304.

9. Stoudemire A, Levenson JL. Clinical Psychiatry for Medical Students. Lippincott-Raven New York; 1998.

10. De Leo S, Lee SY, Braverman LE. Hyperthyroidism. Lancet. 2016;388(10047):906-18.

11. Kailasam MT, Parmer RJ, Stone RA, Shankel S, Kennedy BP, Ziegler MG, et al. Factitious pheochromocytoma: novel mimickry by Valsalva maneuver and clues to diagnosis. Am J Hypertens. 1995;8(6):651-5.

12. Chidakel AR, Pacak K, Eisenhofer G, Lawrence JE, Ayala AR. Utility of plasma free metanephrines in diagnosis of factitious pheochromocytoma. Endocr Pract. 2006;12(5):568-71.

13. Sharma ST, Nieman LK. Cushing's syndrome: all variants, detection, and treatment. Endocrinol Metab Clin North Am. 2011;40(2):379-91.

14. Findling JW, Raff H. Diagnosis of endocrine disease: differentiation of pathologic/neoplastic hypercortisolism (Cushing's syndrome) from physiologic/non-neoplastic hypercortisolism (formerly known as pseudo-Cushing's syndrome). Eur J Endocrinol. 2017;176(5):R205-16.

15. Ameh V, Speak N. Factitious hypoglycaemia in a nondiabetic patient. Eur J Emerg Med. 2008;15(1):59-60.

16. Anderson B, Nostedt J, Girgis S, Dixon T, Agrawal V, Wiebe E, et al. Insulinoma or non-insulinoma pancreatogenous hypoglycemia? A diagnostic dilemma. J Surg Case Reports. 2016;2016(11):rjw188-rjw188.

17. Vella A. Postprandial (reactive) hypoglycemia [Internet]. [cited 2016 Oct 20]. Available from: https://www.uptodate.com/contents/postprandial-reactive-hypoglycemia

18. Kronenberg HM. Williams textbook of endocrinology. Philadelphia: Saunders Elsevier; 2007.

19. Valli V, Blandamura S, Pastorelli D, Merigliano S, Sperti C. Nesidioblastosis coexisting with non-functioning islet cell tumour in an adult. Endokrynol Pol. 2015;66(4):356-60.

20. Wong SL, Priestman A, Holmes DT. Recurrent hypoglycemia from insulin autoimmune syndrome. J Gen Intern Med. 2014;29(1):250-4.

21. Nonislet cell tumor hypoglycemia [Internet]. [cited 2018 Sep 24]. Available from: https://www.uptodate.com/contents/nonislet-cell-tumor-hypoglycemia.

22. Jeon JY, Kim SR, Kim HJ, Kim DJ, Lee K-W, Lee J-D, et al. Risk factors of severe hypoglycemia requiring medical assistance and neurological sequelae in patients with diabetes: A case - control study. Medicine (Baltimore). 2016;95(47):e5365. 